Content list available at: https://openconstructionandbuildingtechnologyjournal.com

RESEARCH ARTICLE

\title{
Cracking in Reinforced Concrete Structures Damaged by Artificial Corrosion: An Overview
}

\author{
Stefania Imperatore ${ }^{1, *}$ and Zila Rinaldi ${ }^{2}$ \\ 'Department of Civil Engineering, "Niccolò Cusano” University of Rome, 00166, Italy \\ ${ }^{2}$ Department of Civil Engineering and Computer Science Engineering, University of Rome “Tor Vergata”, 00133, Italy
}

\begin{abstract}
:
Background:

Corrosion of the reinforcing steel is a significant issue in construction engineering. As the corrosive attack propagates, the oxides accumulated on the steel-concrete interface cause a radial internal pressure in the structural element and induce a tensile stress state in the concrete with the consequent cracking. Except for few cases, the main outcomes on the behavior of reinforced concrete structures damaged by corrosion come from experimental results on artificially corroded specimens. For many years, the scientific community has been discussing the feasibility of artificial techniques to simulate the corrosion process in structural element. Specifically, the most disputed method is the accelerated electrolytic corrosion test, often characterized by high current intensities in order to reduce the duration of the experimental surveys.

\section{Objective:}

In the paper the influence of the current density on the degradation of a reinforced concrete element is investigated with particular reference to the kind of formed oxides and to the crack width.

\section{Methods:}

An experimental survey on steel rebars embedded in concrete cylinders and subjected to an electrolytic corrosion has been performed, with different increasing current densities. Furthermore, an analytical model, based on the classical thick-walled cylinder theory already proposed by the authors, is applied for validating the experimental results.
\end{abstract}

Results:

The oxides produced by artificial corrosion with different current densities are analyzed with X-ray diffractometry measurements. The influence of the current density on the crack widths is also pointed out.

\section{Conclusion:}

The analyses of the obtained results show that for the analysed specimens and current density range, no significant differences are found for the oxides composition. On the contrary the influence of the current density on the crack width is pointed out, and an upper limit of this parameter is indicated.

Keywords: Corrosion, Reinforced concrete, Cracking, Experimental survey, Current density, Analytical model.

\begin{tabular}{|l|l|l|l} 
Article History & Received: October 30, 2018 & Revised: January 01, 2019 & Accepted: March 10, 2019
\end{tabular}

\section{INTRODUCTION}

For several years the reinforced concrete was considered an invulnerable material and all the factors related to the environmental actions and the relative consequences were ignored.

\footnotetext{
* Address correspondence to this author at the Department of Civil Engineering, "Niccolò Cusano" University of Rome, 00166, Italy;

E-mail: stefania.imperatore@unicusano.it
}

Therefore, the study of the durability and the service life of reinforced concrete structures is of great importance (e.g. [1 4]). As an example, in EU a great number of the concrete highway bridges are deteriorated and are considered to be substandard: the $39 \%$ for France, the $37 \%$ for Germany, the $30 \%$ for United Kingdom and the $26 \%$ for Norway [5]. More than $30 \%$ of the American highway bridges have been declared deficient by the U.S. Department of Transportation [6]. 
In the estimation of life-cycle costs and optimization of repair and maintenance strategies for RC structures, severe cracking and spalling are considered as limit states (e.g. [7 9]). The definition of the maximum crack width depends on individual conditions and asset owner policies. Actually, a crack width between 0.3 to $0.4 \mathrm{~mm}$ is defined as the limit value for a durability limit state $[10,11]$. The problem of the relationship between the corrosion phenomenon and the corresponding crack opening has been discussed [12].

In the paper, the topic of the cracking in reinforced concrete structures subjected to the corrosion process is firstly outlined by means of a brief review of the most significant literature results. Except for few cases, the principal findings come out from experimental surveys based on artificial corrosion procedures. Since the corrosion products amount increases with the increase of the current intensity, there is a great influence of the current intensity on the crack width is clear, the oxides must have the time to spread in the concrete. The amount of the oxides (and then the radial pressure) increases with the time proportionally to the current intensity; consequently, the cracks widen and a strong localization of the corrosion at the crack occurs.

Since the simulation of a realistic degradation is strictly related to the effective concrete porosity, to the cover depth and to the current intensity, the accelerated electrolytic corrosion tests have to be carried out by applying low current intensity values. Then, an experimental survey is carried out to estimate the influence of the current intensity on the corrosion morphology, oxides typology and cracking. The classical electro-lytic corrosion technique was applied to embedded rebars in order to attain a level of 5\% in mass loss, applying different corrosion rates. The experimental results suggest that the current density, in the analysed range of up to 4000 $\mu \mathrm{A} / \mathrm{cm}^{2}$, does not influence the typology of the corrosion products - mainly ferrous hydroxide - in agreement with other authors (e.g. [13 - 15]). On the other side, the increase of the corrosion rate induces a significant corrosion localization, with an increase of the crack width.
Finally, to assess the upper limit of the current density for simulating a realistic degradation morphology, an analytical model, based on the classical thick-walled cylinder theory and able to provide the crack opening as a function of the corrosion level, the concrete mechanical properties, the cover/reinforcement-diameter ratio and the oxide typology, is also applied.

\section{LITERATURE REVIEW}

Many experimental and theoretical researches are focused on the assessment of the time in which the concrete cracks, due to the corrosion process.

The theoretical models typically define the stress state in the concrete through the thick-walled cylinder model (internally delimited by the reinforcement bar and, externally, by the concrete cover) subjected to an internal pressure caused by the expansion of the corrosion products. Complex models take into account the reduction of the reinforcement cross-section, the presence of a thin porous layer around the reinforcements (in which the oxides settle without stress the concrete) and the diffusion of the oxides in the cracks. The first conceptual model for the prediction of the service life of corroded structures was developed by Tuutti [16], which distinguished two periods of the corrosive phenomenon (Fig. 1a), in the first stage $\mathrm{CO}_{2}$ or $\mathrm{Cl}^{-}$ions spread and activate the corrosive process; in the second, the corrosion propagates up to the cover cracking. Weyers et al., [17], stated that between the initiation and the propagation period there is a further phase during which the corrosion products are arranged at the steel-concrete interface and do not exert any pressure on the surrounding concrete (Fig. 1b).

The model proposed by El Maaddawy [14] is based on the assumption that the concrete surrounding the reinforcement behaves like a perfectly elastic thin-walled cylinder. In this hypothesis, the time necessary for the concrete cracking $\left(T_{c r}\right)$ is evaluated according to the Faraday's relationship and requires the knowledge of the corrosion products amount.
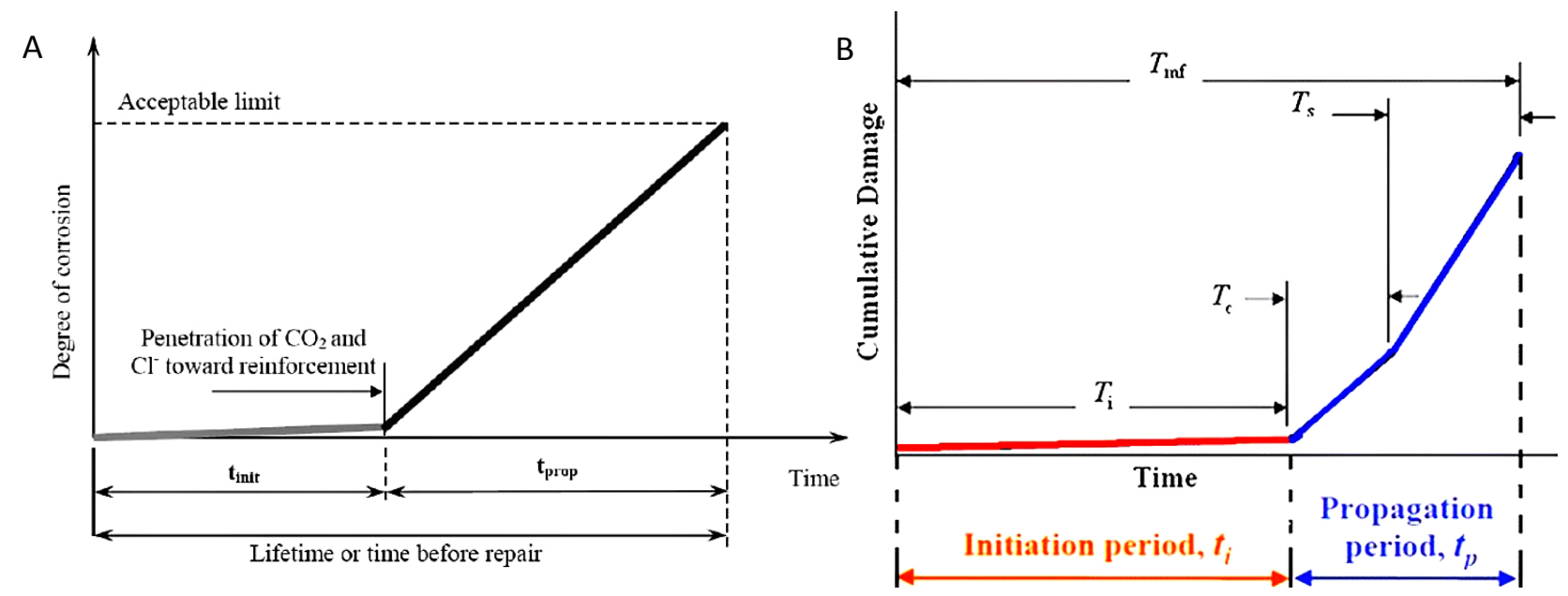

Fig. (1). Schematic representation of the service life of model by Tuutti (a) and Weyers (b). 


$$
\begin{aligned}
T_{c r}= & {\left[\frac{7117.5\left(d+2 \delta_{0}\right)(1+v+\psi)}{i E_{e f}}\right] . } \\
& {\left[\frac{2 c f_{c t}}{d}+\frac{2 \delta_{0} E_{e f}}{(1+v+\psi)\left(d+2 \delta_{0}\right)}\right] }
\end{aligned}
$$

where $d$ is the reinforcement diameter, $\delta$ is the thickness of the porous layer, $v$ is Poisson ratio, $i$ is the current density, $E_{e f}$ is the effective concrete Young's modulus, $c$ is the concrete cover, $f_{c t}$ is the concrete tensile strength and $\psi$ is a parameter that takes into account the concrete cover, the reinforcement and the porous layer.

Successive models (e.g. $[15,18-21])$ introduce the nonlinear behaviour of the concrete in tension.

In order to account for the non-linear behavior of concrete after partial cracking, Chernin et al., [22], considered two concentric cylinders: in the inner cracked cylinder, the concrete is modeled as an inhomogeneous orthotropic linearly elastic material characterized by the tangential modulus of elasticity; the outer uncracked cylinder is instead treated as an isotropic linearly elastic material. Then, the time to crack initiation was evaluated according to the Faraday's law calibrated by mean experimental data:

$$
T_{c r}=\frac{\delta_{c r}}{3.48 \cdot i_{c o r r}\left(\alpha_{v}-1\right)}
$$

where $\alpha_{v}$ is the volumetric expansion ratio of corrosion products, $i_{\text {corr }}$ is the corrosion rate in $\mu \mathrm{A} / \mathrm{cm}^{2}$, and $\delta_{c r}$ (in $\mu \mathrm{m}$ ) is the radial displacement on the inner surface at the full cracking of the cylinder wall.

According to Lu et al., [23], the time from the corrosion initiation to the cover cracking (in years) may be predicted as:

$$
\begin{gathered}
T_{c r}=26.8 \cdot(d+k \cdot c) . \\
\frac{\left\{\left(0.3+0.6 \frac{c}{d}\right) \cdot \frac{f_{c t}}{E_{c e f}}\left[\frac{(0.5 d+c)^{2}+0.25 d^{2}}{(0.5 d+c)^{2}-0.25 d^{2}}+v_{c}\right]+1+\frac{2 \delta_{0}}{d}\right\}^{2}-1}{(n-1) \cdot i_{c o r r}}
\end{gathered}
$$

where $\delta$ is the thickness of the porous zone, $c$ and $d$ are the concrete cover and the diameter reinforcement, respectively; $k$ is a modified coefficient, in the range $0.0-1.0$, which depends on the corrosion conditions for the long-term natural corrosion and short term accelerated corrosion; $f_{c t}, E_{c e}, v_{c}$ are the tensile strength, the Elastic Modulus and the Poisson's ratio of concrete, respectively; $n$ is the mean ratio of the volume of the corrosion products to the consumed iron; $i_{\text {corr }}$ is the corrosion rate in $\mu \mathrm{A} / \mathrm{cm}^{2}$.

Jamali et al., [ 24 ], in agreement with Otieno et al., [25], founds that the experimental models adequately predict the time-to-cracking only in the laboratory conditions. Du et al. [26], developed meso-scale numerical model to analyze the influence of the concrete heterogeneities and the non-uniform corrosion-induced expansion on the cracking. The numerical models highlight that the cracking is realistic when the meso- scale level is considered, but of course, this level of accuracy requires a computational effort too high for the practical applications.

On the basis of previous numerical and experimental results, Bossio et al., $[27,28]$ correlated the crack widths to the corrosion, also considering several cracks and their distance. The proposed formulations show good agreement with our experimental data and tests in the literature. According to the authors the crack opening can be evaluated with EQ. 4 or EQ. 5 in the case of internal and corner bars, respectively:

$$
\begin{aligned}
& w_{c}=y_{\text {lin }} \cdot\left[\left(0.37+0.013 \cdot c_{c}\right) \cdot \ln \left(b_{i}\right)+1.5+0.12 \cdot c_{c}\right] \\
& w_{c}=y_{\text {lin }} \cdot\left[\left(\frac{34+3.6 \cdot c_{c}}{50}\right) \cdot c_{c} \cdot b_{e}^{\left(0.6+0.39 \cdot \ln \left(c_{c}\right)\right)}\right]
\end{aligned}
$$

where $b_{i}(\mathrm{~mm})$ and $b_{e}(\mathrm{~mm})$ are the crack distances, respectively; $c_{c}$ is the concrete cover and $y_{\text {lin }}$ is the oxide layer thickness, that may be evaluated as:

$$
y_{\text {nlin }}=y_{\text {lin }} \cdot\left(w_{c}+1\right)^{\left(\frac{363+1.5 c_{c}}{10000}\right)}
$$

In the experimental studies, the cracks formation, propagation and growth are analyzed varying the corrosion level. A worth mentioning point is that the experimental results from accelerated electrolytic corrosion tests can give unrealistic results for current densities higher than $500 \mu \mathrm{A} / \mathrm{cm}^{2}$ $[29,30]$. Even if nominal intensities of $3-10 \mu \mathrm{A} / \mathrm{cm}^{2}$ represent the common corrosion rate detected in real-size corroding concrete structures, higher values can be applied: Alonso et al., [31] suggested a maximum current intensity of $100 \mu \mathrm{A} / \mathrm{cm}^{2}$, El Maaddawy [32] proposed a current density level above 200 $\mu \mathrm{A} / \mathrm{cm}^{2}$ as a limit in the accelerated electrolytic corrosion test on reinforced concrete elements. With this in mind the results obtained by many authors should be critically reviewed.

Reliable indications have been provided by the Spanish researches, who applied very low corrosion rates. Alonso et al., [31] developed galvanostatic tests characterized by nominal constant current density of $100 \mu \mathrm{A} / \mathrm{cm}^{2}$ and found crack widths of $0.05-0.1 \mathrm{~mm}$ for radius losses of $15-50 \mu \mathrm{m}$ and widths of $0.2-0.3 \mathrm{~mm}$ for penetrations of 50-200 $\mu \mathrm{m}$. Similar results were obtained by Rodriquez et al., [33] on RC beams subjected to accelerated electrolytic corrosion. Moreover, a formulation relating the pit penetration needed for cracking initiation $\left(x_{0}\right.$ expressed in $\mu \mathrm{m})$, the concrete cover ( $c$ expressed in $\mathrm{mm}$ ) and the initial bar diameter ( $\varphi_{0}$ expressed in $\mathrm{mm}$ ) was proposed (EQ. 7).

$$
x_{0}=7,53+9,32 \frac{c}{\phi_{0}}
$$

An alternative formulation was defined by Rodriquez [34] to account for the splitting tensile strength $\left(f_{c, s p}\right.$ expressed in $\mathrm{MPa})$ :

$$
x_{0}=83,8+7,4 \frac{c}{\varphi_{0}}-22,6 f_{c, s p}
$$


Moreover, Rodriquez [34] proposed a relationship between the crack width ( $w$ expressed in $\mathrm{mm})$, the attack penetration $(x$ expressed in $\mu \mathrm{m})$ and $x$ :

$$
w=0,05+\beta\left(x-x_{0}\right)
$$

where, $\beta$ is a coefficient that account for the reinforcement position ( $\beta=0.01$ for top cast bars and 0.0125 for bottom cast bars).

In EQ.9 the attack penetration $x$ may be evaluated as:

$$
x=\frac{\phi_{0}}{\alpha}\left[1-\sqrt{1-\frac{\Delta A_{s}}{A_{s}}}\right]
$$

where $\phi_{0}$ is the initial reinforcement diameter and $\alpha$ is a coefficient to account for the corrosion morphology ( 2 for uniform corrosion and 4-8 for pitting corrosion). $\Delta A_{s}$ and $A_{s}$ are the corroded and the initial cross section of the reinforcement, respectively.

An interesting study was performed by $\mathrm{Vu}$ and $\mathrm{Val}[35$,
36], who experimentally and numerically investigated the crack initiation and propagation, quantifying also the corrosion products dissipated within the cracks. Eight $700 \times 1000 \times 250$ $\mathrm{mm}^{3}$ slabs, reinforced only on the top with four $16 \mathrm{~mm}$ diameter round steel bars spaced $150 \mathrm{~mm}$, were subject to an accelerated corrosion process characterized by a current density of $100 \mu \mathrm{A} / \mathrm{cm}^{2}$. The first visible crack had a width of about $0.05 \mathrm{~mm}$; the cracks propagated (in width and length) along a longitudinal fracture approximately $0.25-0.4 \mathrm{~mm}$ wide (Fig. 2).

On the basis of the obtained experimental results, $\mathrm{Vu}$ [35] defined an empirical relationship (EQ. 11) able to establish the time necessary to obtain a limit crack width of as a function of the concrete quality:

$$
t_{\text {serv }}=A\left(\frac{c}{w c}\right)^{B}
$$

where, $c$ represent the concrete cover, $w c$ the water/cement ratio. $\mathrm{A}$ and $\mathrm{B}$ are parameter specifically defined in Table $\mathbf{1}$ for the considered limit crack widths $\left(w_{\text {lim }}\right)$.

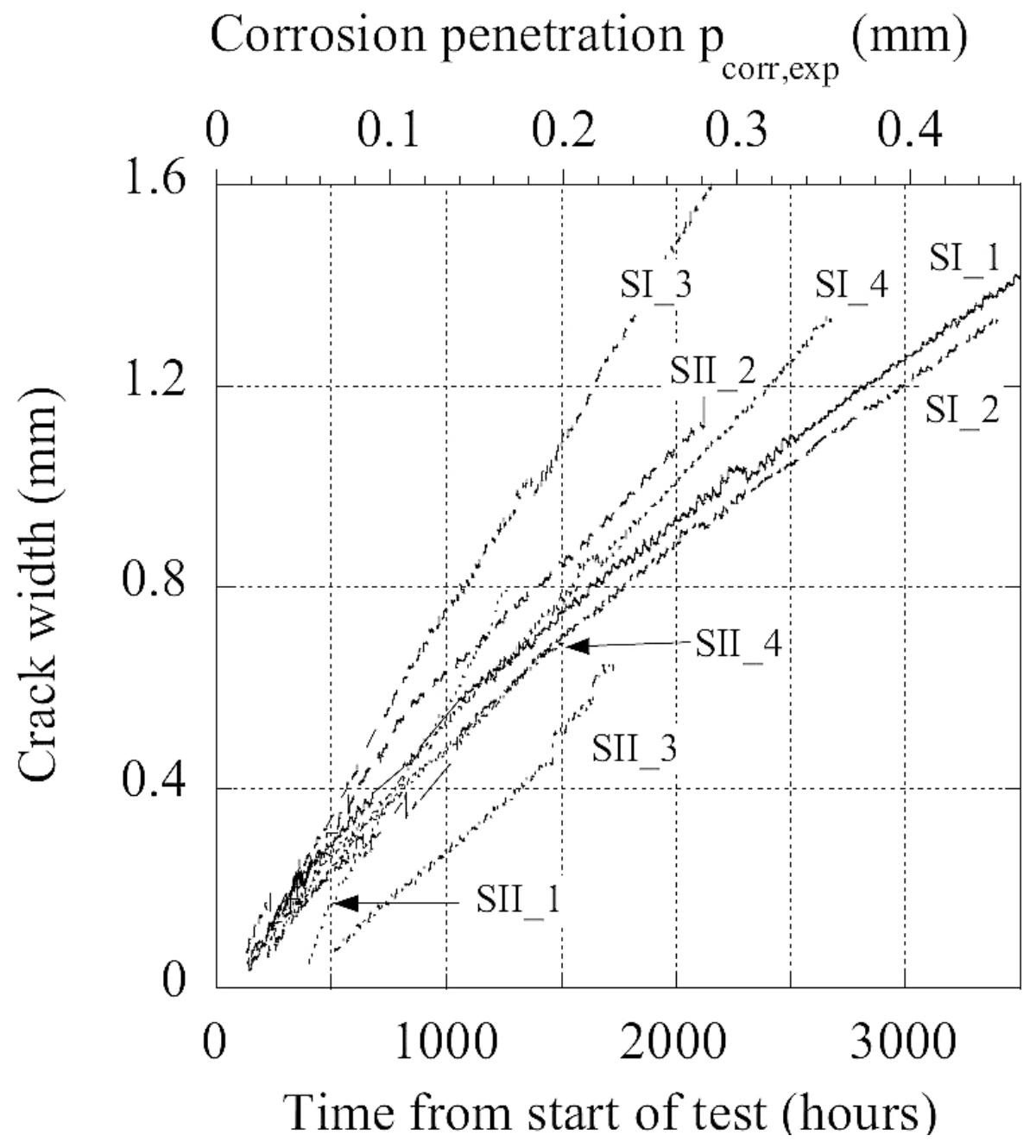

Fig. (2). Crack propagation in the experimental test [35]. 

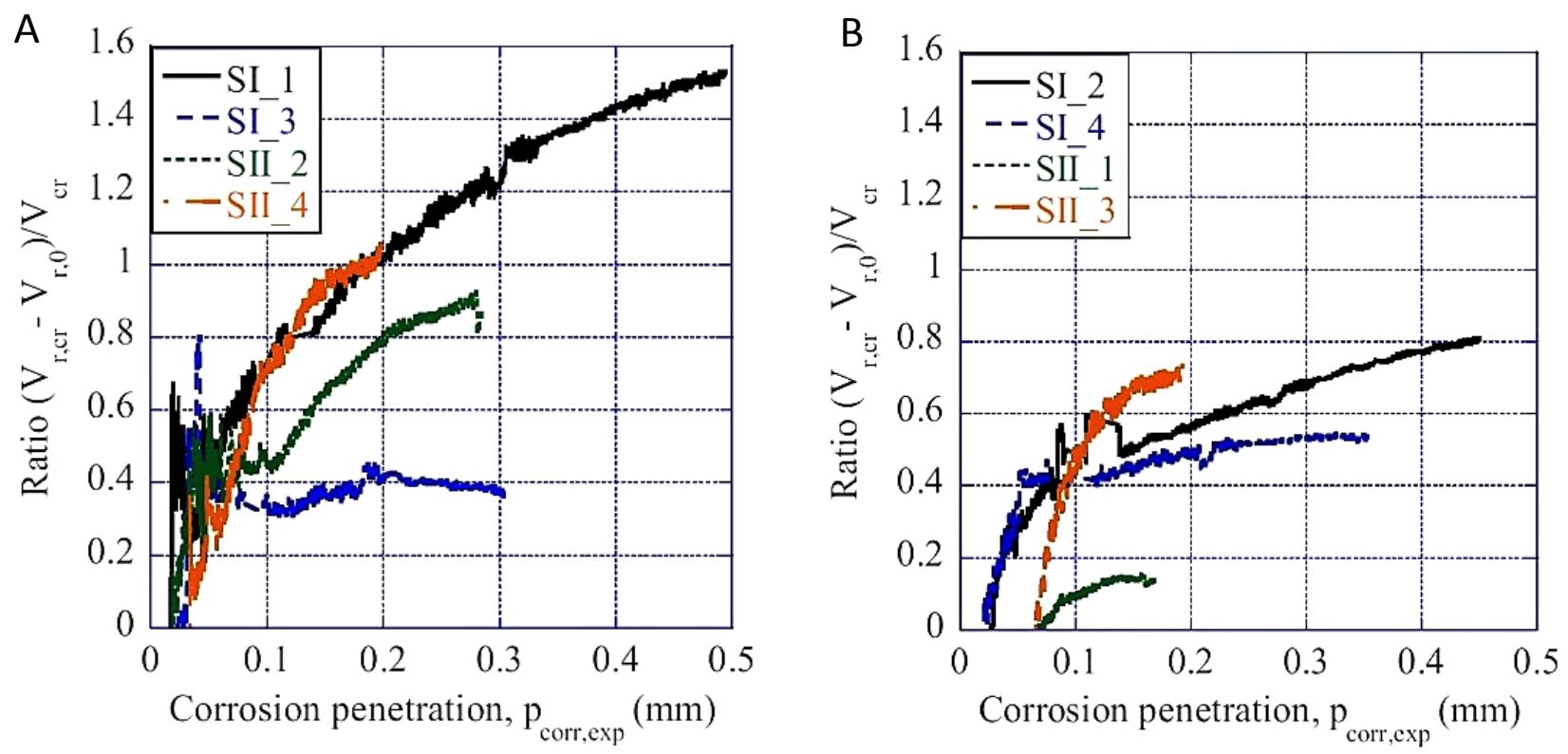

Fig. (3). Penetration of corrosion products into cracks for RC slabs with $25 \mathrm{~mm}$ (a) and $50 \mathrm{~mm}$ (b) concrete cover [36].

Table 1. Parameters for the EQ.11 [35].

\begin{tabular}{|c|c|c|}
\hline Limit Crack Width & A & B \\
\hline$w_{\text {lim }}=0.3 \mathrm{~mm}$ & 65 & 0.45 \\
\hline$w_{\text {lim }}=0.5 \mathrm{~mm}$ & 225 & 0.29 \\
\hline$w_{\text {lim }}=1.0 \mathrm{~mm}$ & 700 & 0.23 \\
\hline
\end{tabular}

To predict the penetration of corrosion products into the crack, the experimental results were also simulated by mean FEM models. In Fig. (3) the ratio of the volume of corrosion products penetrating into cracks after crack initiation with respect to the total cracks volume is represented as a function of the corrosion attack: since the corrosion products gradually fill the cracks, the classical hypothesis of the analytical model can underestimate the predicted crack width.

Finally, it is interesting to mention the results obtained by various authors who submitted structural elements to a natural long-term corrosion process. In their experimental surveys, Ortega et al., [37] finds corrosion cracks already after one year of exposure; during the five-year research, the crack pattern, increased constantly in the time according to a linear law. After a natural corrosion of 14 and 17 years Vidal et al., [38] finds that the Rodriquez's formulation gives reliable results only for the bottom cast reinforcement and propose a model of crack initiation for the localized corrosion. According to Vidal et al., $[38,39]$, the cross-section loss $\Delta A_{s 0}$ can be calculated as

$$
\Delta A_{s e 0}=A_{s}\left\{1-\left[1-\frac{\alpha}{\phi_{0}}\left(7.53+9.32 \frac{c}{\phi_{0}}\right) 10^{-3}\right]^{2}\right\}
$$

where $A_{s}$ is the sound steel cross-section ( $\left.\mathrm{mm} 2\right), \phi_{0}$ is the initial reinforcement diameter $(\mathrm{mm}), \mathrm{c}$ is the concrete cover $(\mathrm{mm})$ and $\alpha$ is the pit penetration depth parameter.
In the Vidal's model, it is assumed that crack width is directly proportional to the steel corrosion:

$$
w=0.0575\left(A_{s}-\Delta A_{s e 0}\right)
$$

Subsequent studies performed by Zhang [40] on the same beams have shown that the corrosion morphology change (from a pitting corrosion to a generalized corrosion) with the cracking propagation. After 26 years Khan [41] finds that the Rodriquez's formulation accurately predicts the crack width only if the attack penetration parameter is fixed equal to 8 , while the Vidal et al. model appears in a quite good agreement with the experimental results.

\section{EXPERIMENTAL SURVEY}

An analytical model is carried out in order to investigate the effects of the corrosion rate on the cracking, the corrosion morphology, the oxides typology and their diffusion inside the concrete (Table 2). A total of 10 reinforced concrete cylindrical specimens, characterized by a diameter of $50 \mathrm{~mm}$ and a length of $200 \mathrm{~mm}$, were cast. At the center of each specimen, a $12 \mathrm{~mm}$ diameter bar $\left(\mathrm{f}_{\mathrm{y}}=500 \mathrm{MPa}\right)$ was embedded. The concrete was realized with a CEM I 52,5 Portland cement and a water-tobinder ratio of 0.46 ; due to the small dimension of the specimens, only the fine aggregates $(0.00-4.00 \mathrm{~mm})$ were provided according to an aggregate-to-binder ratio of 0.47 . The mean compressive strength after $28 \mathrm{gg}$ of curing was $20 \mathrm{MPa}$.

The samples were conditioned for $24 \mathrm{~h}$ in a $3 \%$ electrolyte solution and subjected to an accelerated corrosion test with different current densities, as defined in Table 3. After the test, the samples were dried at a constant temperature of $18^{\circ} \mathrm{C}$ for $72 \mathrm{~h}$ and the crack pattern was been accurately acquired and measured (Fig. 4). 
Table 2. Corrosion variables for the samples.

\begin{tabular}{|c|c|c|c|c|}
\hline Specimen & Current Density & Theoretical Corrosion Level & Effective Corrosion Level & Crack Width \\
\hline $\begin{array}{l}\mathrm{A} 1 \\
\mathrm{~A} 2\end{array}$ & $500 \mu \mathrm{A} / \mathrm{cm}^{2}$ & \multirow{4}{*}{$5 \%$} & $\begin{array}{l}5.82 \% \\
4.57 \% \\
\end{array}$ & $\begin{array}{l}0.60 \mathrm{~mm} \\
0.35 \mathrm{~mm}\end{array}$ \\
\hline $\begin{array}{l}\text { B1 } \\
\text { B2 } \\
\end{array}$ & $1000 \mu \mathrm{A} / \mathrm{cm}^{2}$ & & $\begin{array}{l}4.96 \% \\
3.85 \% \\
\end{array}$ & $\begin{array}{l}1.00 \mathrm{~mm} \\
0.30 \mathrm{~mm}\end{array}$ \\
\hline $\begin{array}{l}\mathrm{C} 1 \\
\mathrm{C} 2 \\
\end{array}$ & $2000 \mu \mathrm{A} / \mathrm{cm}^{2}$ & & $\begin{array}{l}4.02 \% \\
6.64 \% \\
\end{array}$ & $\begin{array}{l}0.35 \mathrm{~mm} \\
1.20 \mathrm{~mm} \\
\end{array}$ \\
\hline $\begin{array}{l}\text { D1 } \\
\text { D2 } \\
\text { D3 } \\
\text { D4 }\end{array}$ & $4000 \mu \mathrm{A} / \mathrm{cm}^{2}$ & & $\begin{array}{l}6.82 \% \\
4.68 \% \\
6.07 \% \\
4.15 \%\end{array}$ & $\begin{array}{l}2.50 \mathrm{~mm} \\
1.50 \mathrm{~mm} \\
2.00 \mathrm{~mm} \\
1.30 \mathrm{~mm}\end{array}$ \\
\hline
\end{tabular}

Table 3. Corrosion products and their volumetric ratio respect the iron [21].

\begin{tabular}{|c|c|c|c|c|c|c|}
\hline & $\mathbf{F e O}$ & $\mathrm{Fe}_{3} \mathbf{O}_{4}$ & $\mathrm{Fe}_{2} \mathbf{O}_{3}$ & $\mathbf{F e}(\mathbf{O H})_{2}$ & $\mathbf{F e}(\mathbf{O H})_{3}$ & $\mathbf{F e}(\mathbf{O H})_{3} \cdot 3 \mathbf{H}_{2} \mathbf{O}$ \\
\hline$\alpha_{1}$ & 1.80 & 2.00 & 2.20 & 3.75 & 4.2 & 6.4 \\
\hline
\end{tabular}

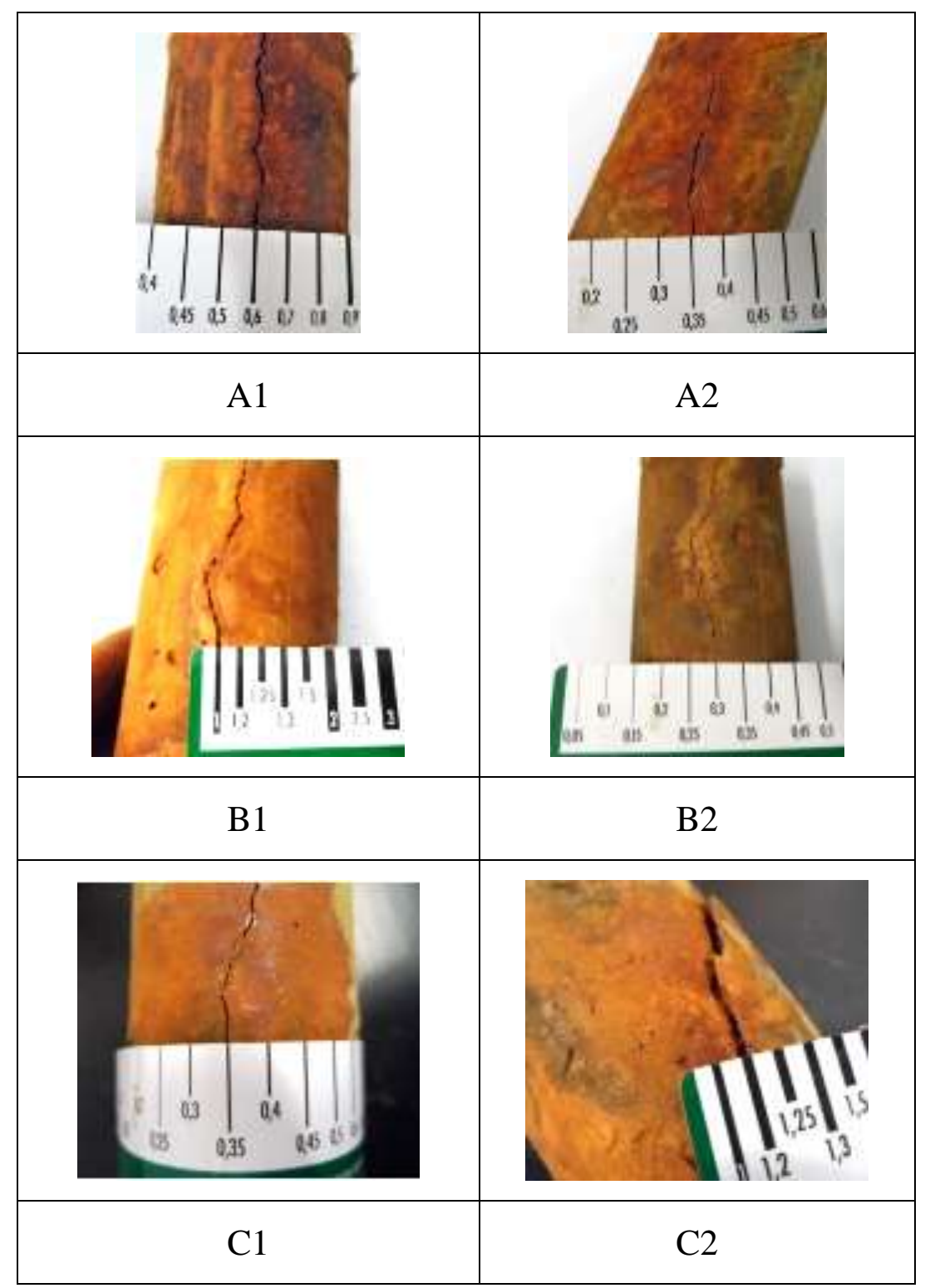




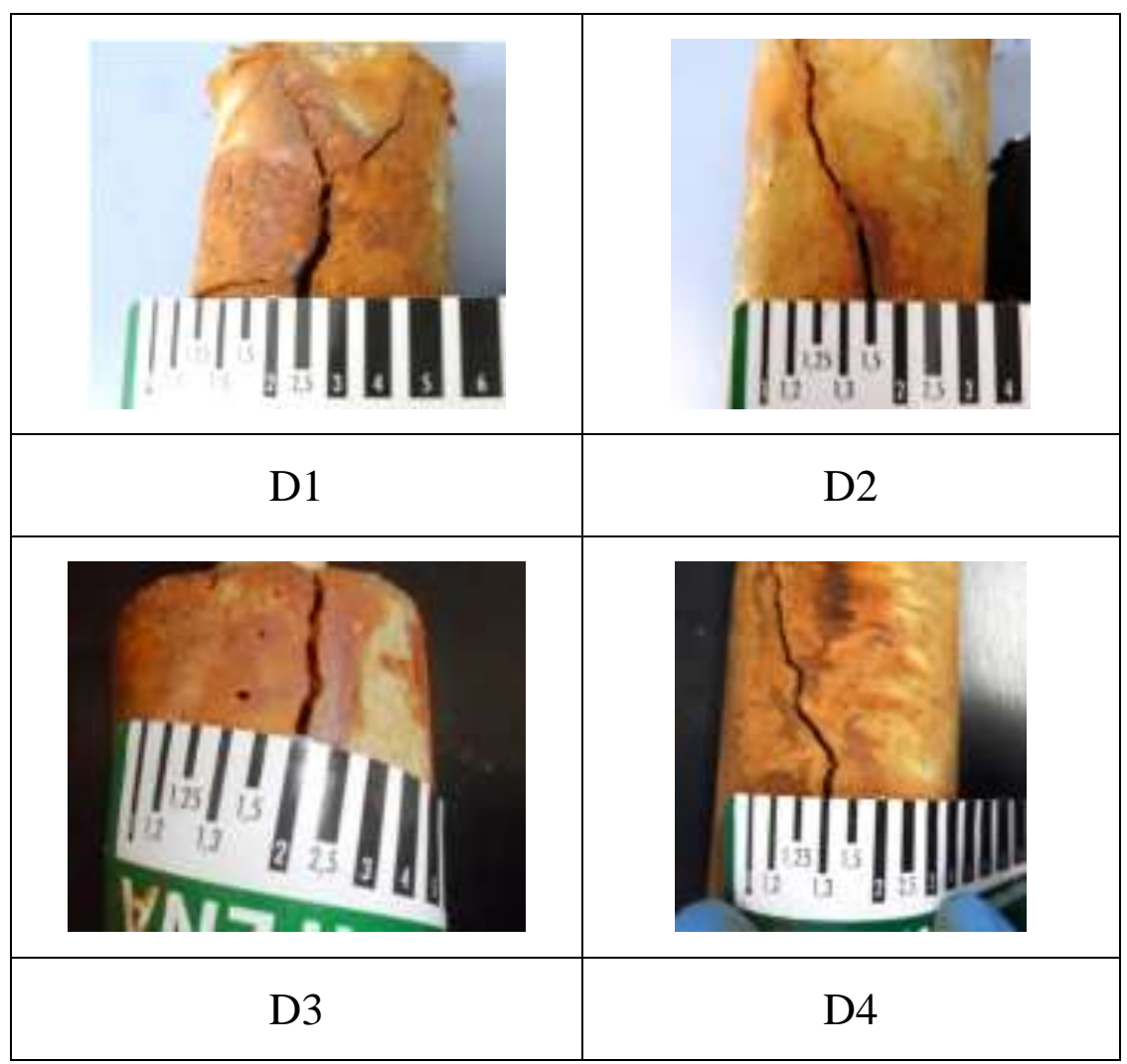

Fig. (4). Crack pattern on the samples.

The experimental survey shows crack widths varying between 0.30 and $2.00 \mathrm{~mm}$, depending on the current intensity applied. In all the samples, the crack pattern is composed of two opposite longitudinal cracks spreading in all the specimen length and bifurcating at the specimen edges. Increasing the current density, the cracks become wider since the oxides fail to spread in the concrete pore and therefore exert a significant radial pressure, even for low degradation levels. The analysis of the propagation of the oxides inside the specimens shows a random diffusion apparently independent of the current intensity. (Fig. 5). As a matter of fact, the diffusion of the corrosion products is related to the casual arrangement of the aggregates and to the produced macro and micro-cracks.

A concentration of brown rust at the reinforcing bar with degrading colors up to yellow along the surface of the cracks was detected in all the samples. The analysis of the oxides showed two different morphologies, scaly (Fig. 6a) and porous (Fig. 6b) ones, that were analyzed through diffractometry measurements. The results are here reported for the corrosion product formed in the samples subjected to two corrosion rates $\left(500 \mu \mathrm{A} / \mathrm{cm}^{2}\right.$ and $\left.2000 \mu \mathrm{A} / \mathrm{cm}^{2}\right)$.

In the graphs (Figs. 7-10), the blue curve represents the background noise, while the different peaks, of different colors, represent the phases, that is the different types of oxides formed. Except for the scaly oxide extracted from the sample subjected to the higher corrosion rate (the Iron Chloride Hydrate, $\mathrm{H}_{2} \mathrm{Cl}_{2} \mathrm{FeO}$ ), all the corrosion products have different phases among which quartz and calcite are prevalent for the presence of the concrete. Specifically, the prevailing phase is the ferrihydrite $\left(\mathrm{Fe}_{2} \mathrm{O}_{3} \cdot 0.5 \mathrm{H}_{2} \mathrm{O}\right)$, eventually accompanied by the magnetite. This result is of particular importance because it allows us to define unambiguously the volumetric ratio between the prevalent oxide (characterized by a density of $3.70-3.90 \mathrm{~g} / \mathrm{cm}^{3}$ depending on the hydration degree) and the iron, which for the examined cases vary between 2.00 and 2.15.

Finally, the corrosion morphology detected on the bars is analyzed (Fig. 11). As previously stated, higher current densities cause larger crack widths. In this condition, a strong corrosion localization is expected since a part of the reinforcement remains exposed and becomes highly subjected to the corrosive phenomenon. It is clear therefore that a higher corrosion rate corresponds to higher corrosion localization, even for low levels of degradation.

Aim of the experimental research is the evaluation of the effects of high current densities in accelerated corrosion, on the of crack pattern, corrosion morphology and (eventually) oxides. Due to the reason, the lower corrosion intensity applied to the sample was $500 \mu \mathrm{A} / \mathrm{cm}^{2}$. Smaller values were already used in the past by the authors in the framework of the experimental analysis of the bond behavior of corroded reinforced concrete elements [42]. In that case, a very low value of current density of about $20 \mu \mathrm{A} / \mathrm{cm}^{2}$ was applied, in agreement with Alonso [31]. For corrosion level slightly lower than $1.00 \%$ in terms of mass loss, the specimens presented a crack width of about $0.10 \mathrm{~mm}$ (Fig. 12). These results will be discussed and compared with the ones previously described, in the following sections. 


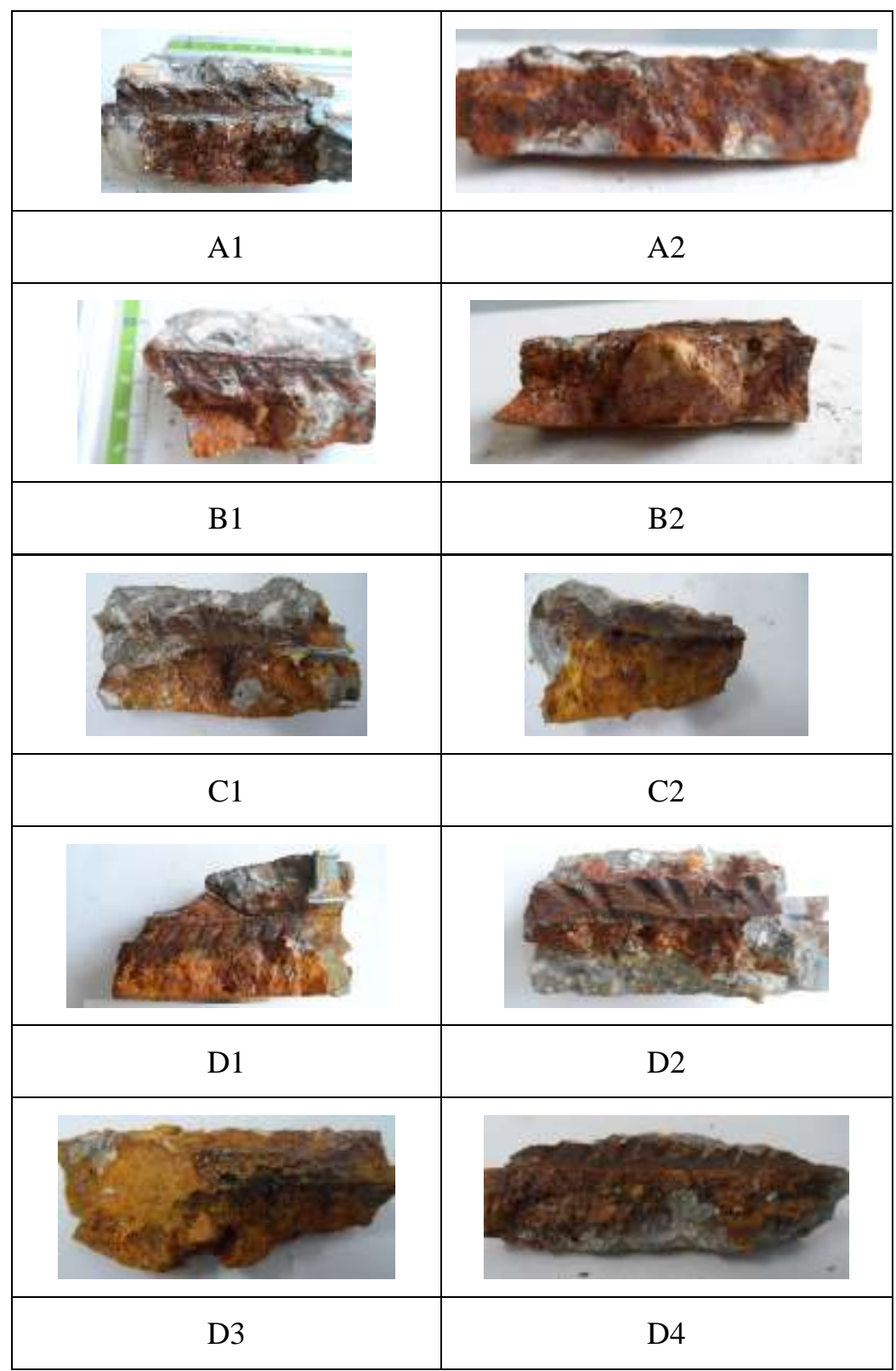

Fig. (5). Corrosion products propagation in the samples.
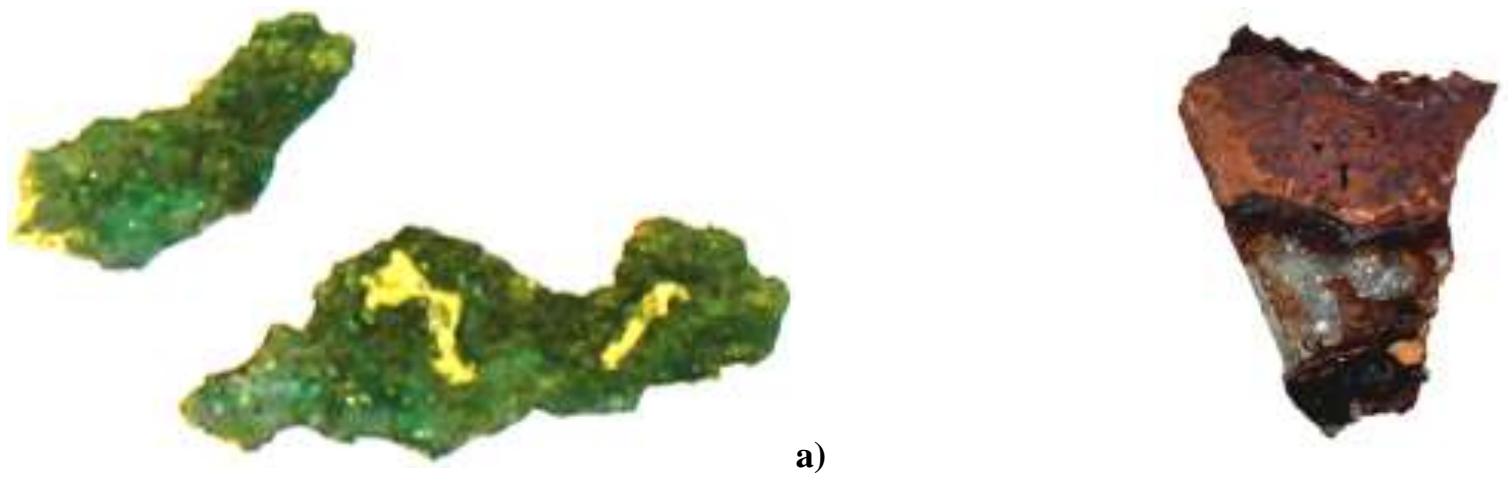

a)

b)

Fig. (6). Corrosion products formed in the samples: (a) scaly oxides; (b) porous oxides. 


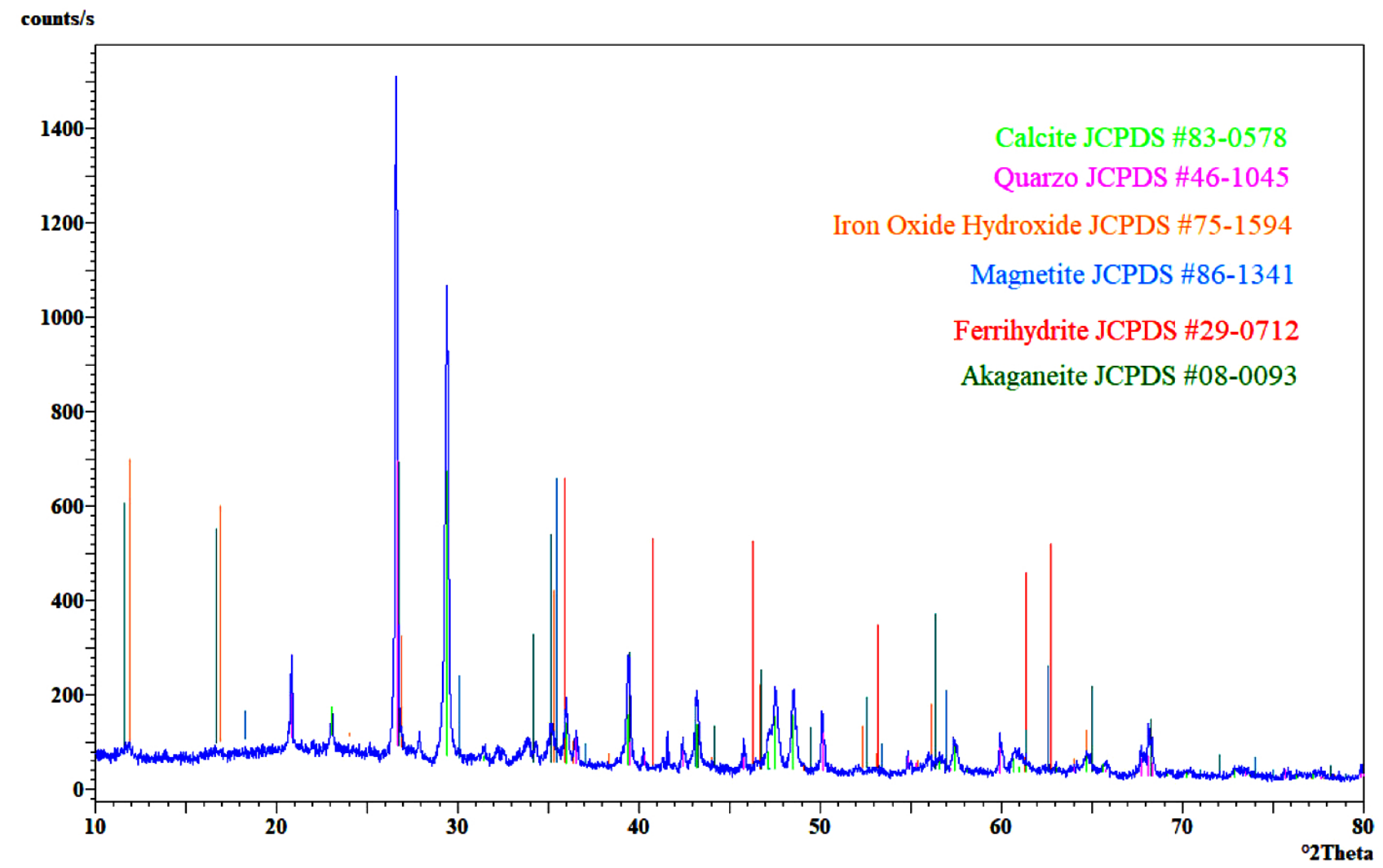

Fig. (7). X-ray diffractometry measurements on the scaly oxide formed with a corrosion rate of $500 \mu \mathrm{A} / \mathrm{cm}^{2}$.

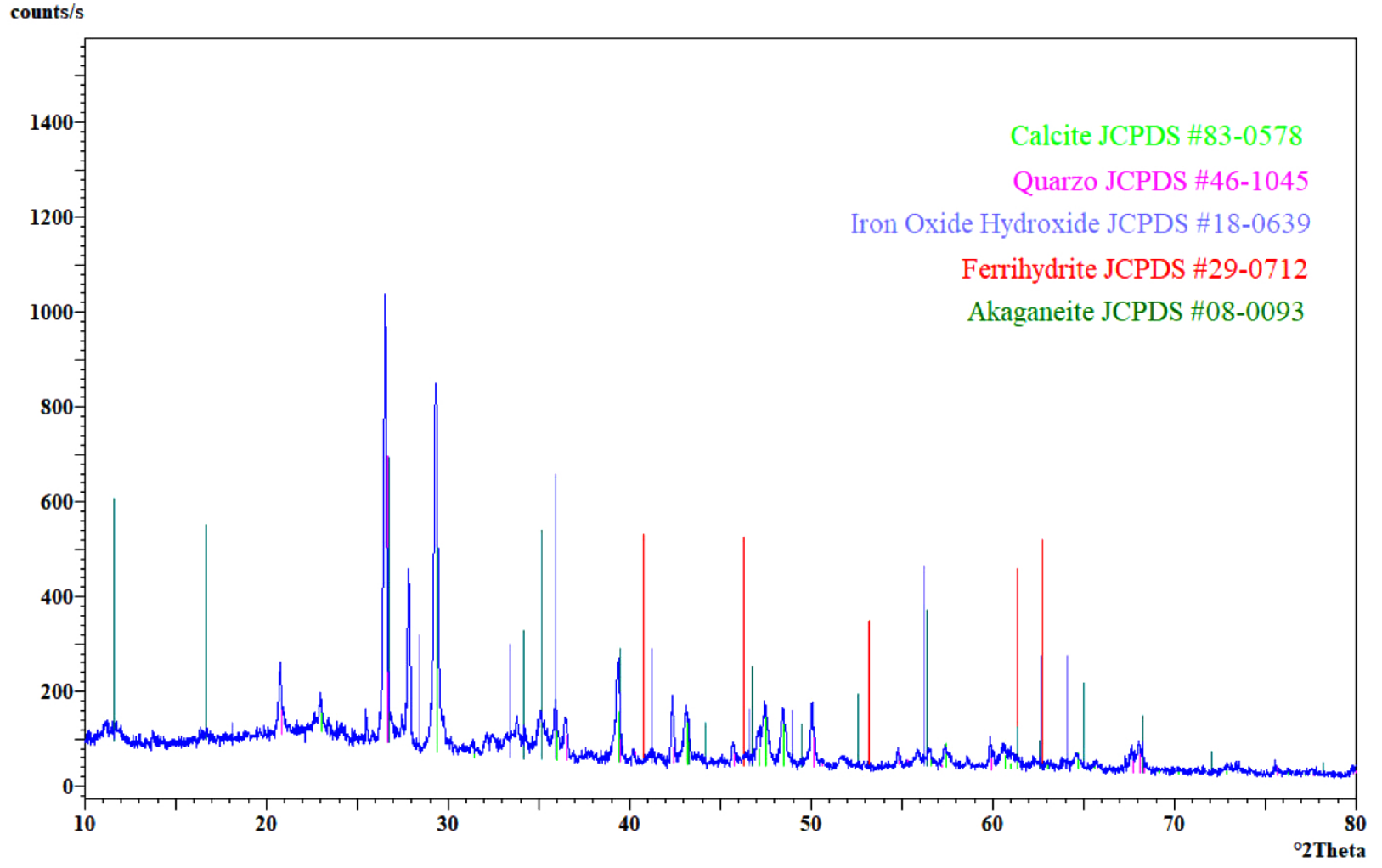

Fig. (8). X-ray diffractometry measurements on the porous oxide formed with a corrosion rate of $500 \mu \mathrm{A} / \mathrm{cm}^{2}$. 


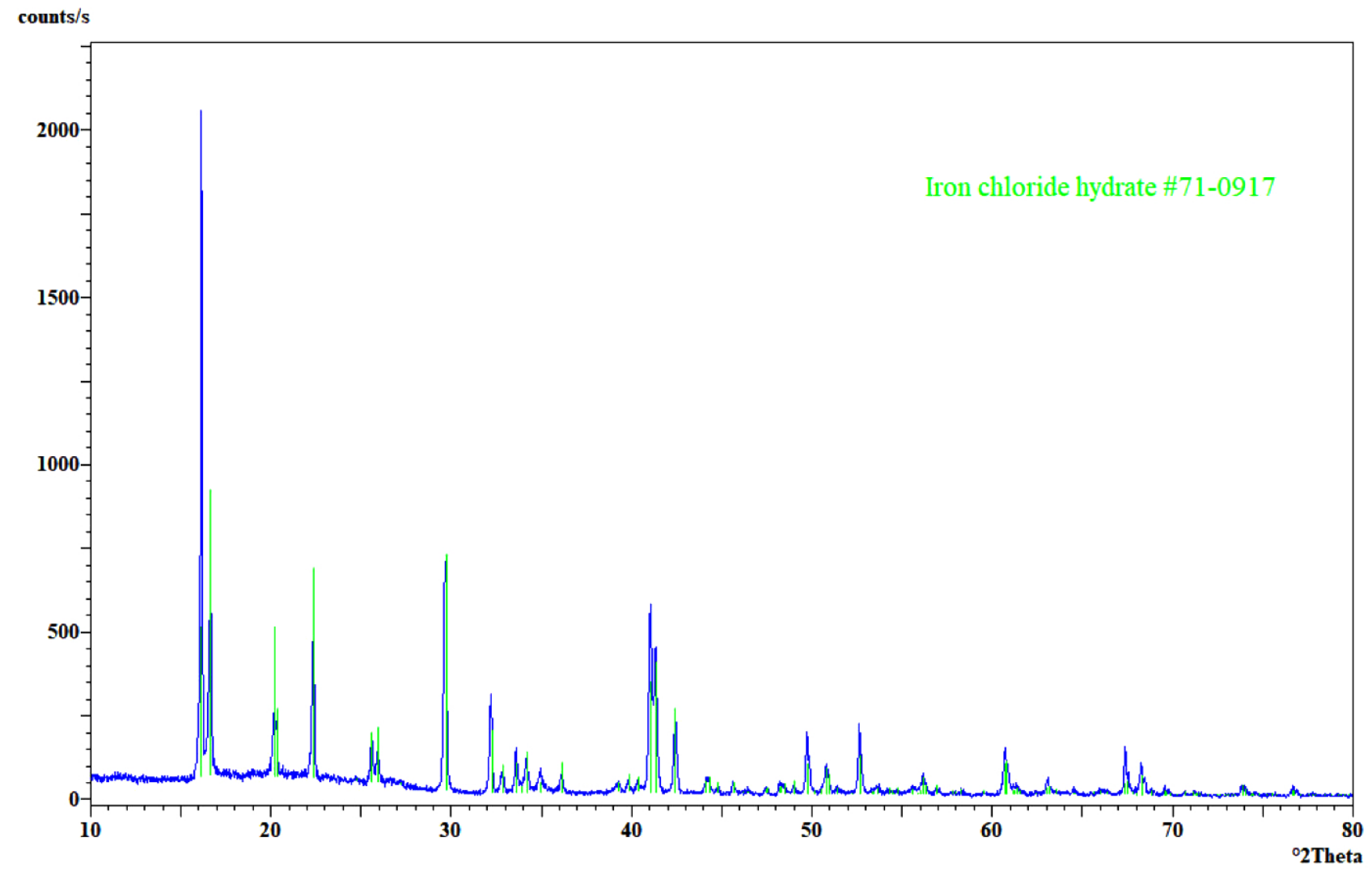

Fig. (9). X-ray diffractometry measurements on the porous oxide formed with a corrosion rate of $2000 \mu \mathrm{A} / \mathrm{cm}^{2}$.

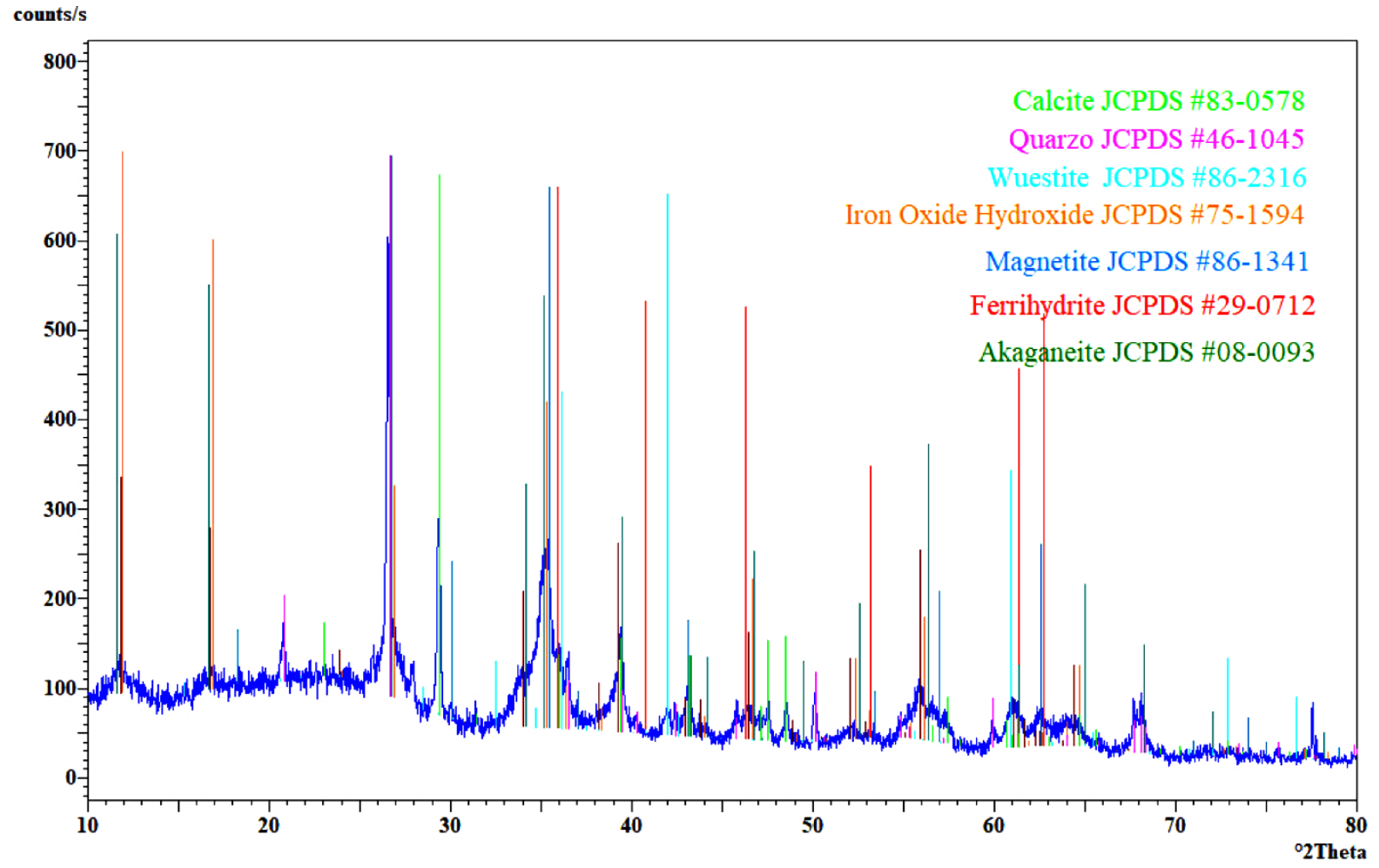

Fig. (10). X-ray diffractometry measurements on the scaly oxide formed with a corrosion rate of $2000 \mu \mathrm{A} / \mathrm{cm}^{2}$. 


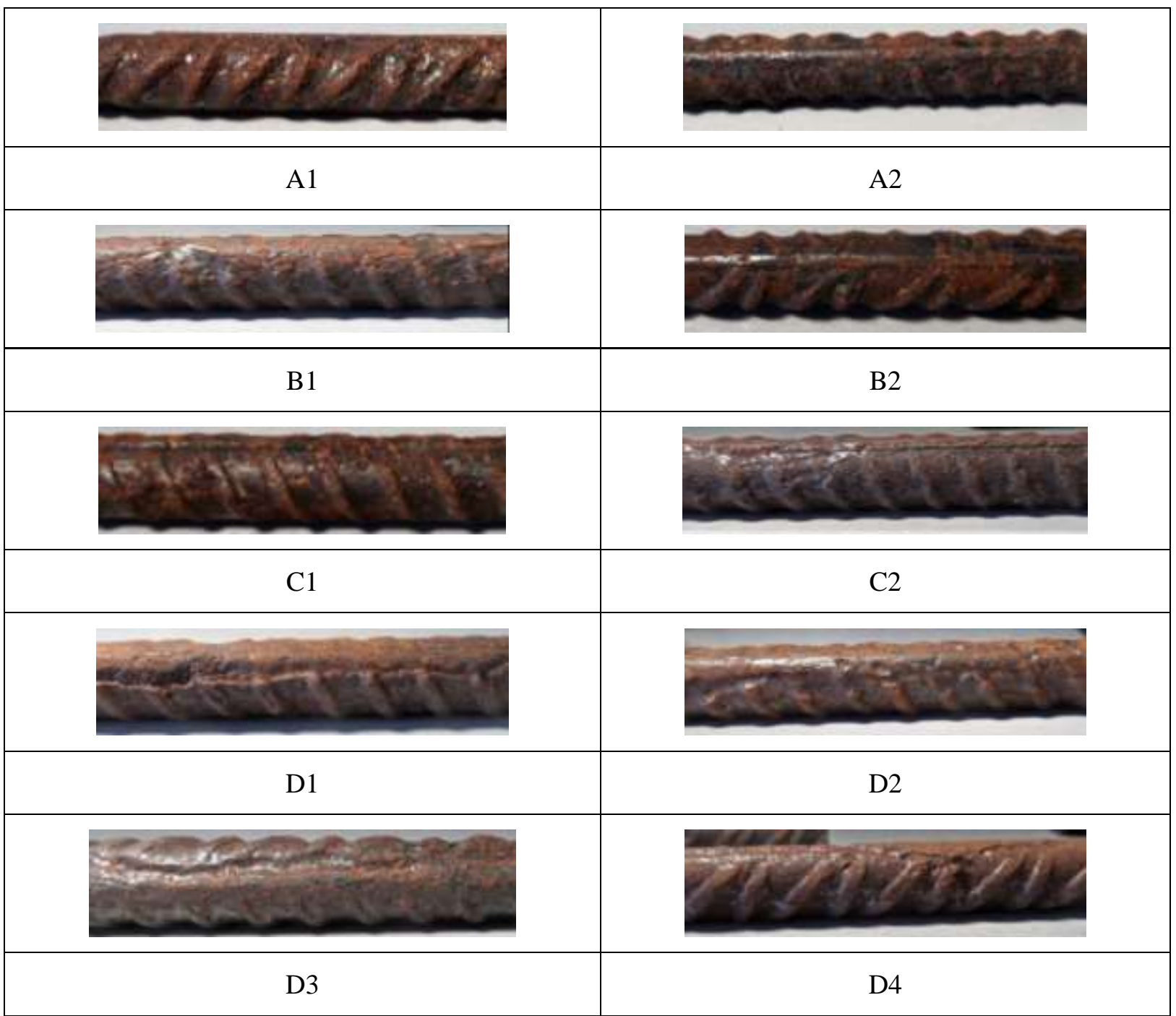

Fig. (11). Corrosion morphology in the samples.

\section{ANALYTICAL MODEL}

According to previous studies of the authors [42], the relationship between the internal pressure due to the expansion of the corrosion product and the degradation level may be evaluated by mean the thick-walled cylinder theory modified in order to account for the nonlinear behavior of the concrete in tension [43].

In absence of any external load and cracks, during the corrosion process the oxides occupy a volume:

$$
\begin{gathered}
\alpha_{1} \pi\left(\phi_{\text {in }} x_{\text {corr }}-x_{\text {corr }}^{2}\right)=\pi\left(\varphi_{i n} U_{r}+U_{r}^{2}\right) \\
+\pi\left(\phi_{\text {in }} x_{\text {corr }}-x_{\text {corr }}^{2}\right)
\end{gathered}
$$

where $\phi_{i n}$ is the sound diameter of the specimen,

$U_{r}$ is the radial displacement due to the expansion of the corrosion products due to an internal pressure that in the elastic stage $\left(\varepsilon \leq \varepsilon_{\mathrm{ct}}\right)$ can be defined as:

$$
p_{\text {corr }}=E_{c} \varepsilon\left[\left(\frac{c^{2}+r^{2}}{c^{2}-r^{2}}+v\right)^{-1}\right]
$$

where $E_{c}$ and $v$ are the Concrete Elastic Modulus and Poisson's ratio respectively; $c$ is the concrete cover and $r$ is the reinforcement radius.

The parameter $\alpha_{1}$ represents the ratio between the volume of the oxides produced and the volume of iron consumed; its value (Table 3) depends on the oxide that is produced.

Then, in the elastic stage corrosion attack may be defined as:

$$
x_{\text {corr }}=\frac{\phi_{\text {in }}}{2}-\sqrt{\frac{\phi_{i n}^{2}}{4}-\frac{U_{r}^{2}+\phi_{i n} U_{r}}{\alpha_{1}-1}}
$$




\begin{tabular}{|c|c|c|c|}
\hline Specimen & Crack Pattern & Crack width & $\% \mathbf{M}_{\text {corr,exp }}$ \\
\hline M4 & & 0.10 & 0.80 \\
\hline M5 & & 0.15 & 0.88 \\
\hline M6 & & 0.20 & 0.94 \\
\hline
\end{tabular}

Fig. (12). Corrosion degradation for some samples experimented in (Coccia et al., 2016).

Subsequently to the cracking, always assuming the absence of any external load, a certain number of cracks $n$, characterized by an average crack width $\left(w_{m}\right)$ and length $\left(l_{c r}\right)$, is introduced in EQ. 14, to account the spreading of the corrosion products. Then, the relationship between the corrosion attack and the average crack width will become:

$$
x_{\text {corr }}=\frac{\phi_{i n}}{2}-\sqrt{\frac{\phi_{i n}^{2}}{4}-\frac{U_{r}^{2}+\phi_{i n} U_{r}+n w_{m} l_{c r} / \pi}{\alpha_{1}-1}}
$$

Where the radial displacement $U_{r}$ will depend on a radial pressure defined according to the equation EQ. 18 for the partially cracked stage and to EQ. 19 for the entirely cracked stage:

$$
\begin{gathered}
p_{c o r r}=\frac{r_{c r}}{r} f_{c t}\left(\frac{c^{2}-r_{c r}{ }^{2}}{c^{2}+r_{c r}{ }^{2}}\right)+ \\
f_{c t}\left[a_{1} r \frac{\pi \varepsilon_{c t}}{n w_{0}}\left(\frac{r_{c r}}{r}-1\right)^{2}+\left(\frac{r_{c r}}{r}-1\right)\right]
\end{gathered}
$$

$$
\begin{aligned}
& p_{c o n r}=f_{c t}\left[\left(a_{i} \frac{2 \pi \varepsilon_{c t} r_{c r}}{n w_{0}}+b_{i}\right)\right. \\
& \left.\left(\frac{c}{r}-1\right)+a_{i} \frac{\pi \varepsilon_{c t} r}{n w_{0}}\left[\left(\frac{c}{r}\right)^{2}-1\right]\right]
\end{aligned}
$$

In fact, in both the stages the relationship between displacement and pressure depends on the contributions of two concentric cylinders: in the partially cracked phase, a perfectly elastic and a cracked cylinder (characterized by a linear softening behavior) are considered; in the entirely cracked stage, two cylinders will be characterized by two different two branches are introduced. Due to this reason, in EQ. 18 and EQ. 19 the terms $a_{i}$ and $b_{i}(i=1,2)$ represent the coordinate of the intersection point yields for the two branches of the softening curve with respect to the fictitious crack width $w$ [44].

Table 4. Mechanical properties of the concrete in the experimental specimens.

\begin{tabular}{|c|c|c|c|}
\hline $\mathrm{f}_{\mathrm{c}}$ & $\mathrm{f}_{\mathrm{ct}}$ & $\mathrm{E}_{\mathrm{c}}$ & $\mathrm{G}_{\mathrm{f}}$ \\
\hline 20 & $1.26 \mathrm{MPa}$ & $17880 \mathrm{MPa}$ & $0.121 \mathrm{~N} / \mathrm{m}$ \\
\hline
\end{tabular}


Table 5. Comparison between the analytical and the experimental results in terms of crack width: present work.

\begin{tabular}{|c|c|c|c|c|}
\hline \multirow{2}{*}{ Specimen } & \multirow{2}{*}{ Effective Corrosion Level } & \multicolumn{3}{|c|}{ Crack Width } \\
\cline { 3 - 5 } & & Observed & Theoretical $\boldsymbol{\alpha}_{\mathbf{1}}=\mathbf{2 . 0 0}$ & Theoretical $\boldsymbol{\alpha}_{\mathbf{1}}=\mathbf{2 . 1 5}$ \\
\hline M1 [42] & $0.80 \%$ & $0.15 \mathrm{~mm}$ & $0.139 \mathrm{~mm}$ & 0.168 \\
\hline $\mathrm{M} 2[42]$ & $0.88 \%$ & $0.18 \mathrm{~mm}$ & $0.153 \mathrm{~mm}$ & 0.185 \\
\hline $\mathrm{M} 3[42]$ & $0.94 \%$ & $0.20 \mathrm{~mm}$ & $0.164 \mathrm{~mm}$ & 0.198 \\
\hline A1 & $5.82 \%$ & $0.60 \mathrm{~mm}$ & $0.304 \mathrm{~mm}$ & $0.575 \mathrm{~mm}$ \\
\hline A2 & $4.57 \%$ & $0.30 \mathrm{~mm}$ & $0.238 \mathrm{~mm}$ & $0.293 \mathrm{~mm}$ \\
\hline B1 & $4.96 \%$ & $1.00 \mathrm{~mm}$ & $0.259 \mathrm{~mm}$ & $0.384 \mathrm{~mm}$ \\
\hline B2 & $3.85 \%$ & $0.30 \mathrm{~mm}$ & $0.200 \mathrm{~mm}$ & $0.297 \mathrm{~mm}$ \\
\hline C1 & $4.02 \%$ & $0.35 \mathrm{~mm}$ & $0.209 \mathrm{~mm}$ & $0.310 \mathrm{~mm}$ \\
\hline C2 & $6.64 \%$ & $1.20 \mathrm{~mm}$ & $0.348 \mathrm{~mm}$ & $0.516 \mathrm{~mm}$ \\
\hline D1 & $6.82 \%$ & $2.50 \mathrm{~mm}$ & $0.357 \mathrm{~mm}$ & $0.530 \mathrm{~mm}$ \\
\hline D2 & $4.68 \%$ & $1.50 \mathrm{~mm}$ & $0.244 \mathrm{~mm}$ & $0.362 \mathrm{~mm}$ \\
\hline D3 & $6.07 \%$ & $2.00 \mathrm{~mm}$ & $0.317 \mathrm{~mm}$ & $0.471 \mathrm{~mm}$ \\
\hline D4 & $4.15 \%$ & $1.30 \mathrm{~mm}$ & $0.216 \mathrm{~mm}$ & $0.321 \mathrm{~mm}$ \\
\hline
\end{tabular}

\section{DISCUSSION}

\subsection{Comparison Between the Analytical Model and the Experimental Results}

The analytical model synthesized in the previous section, has been adopted for the evaluation of the influence of the current intensity on the crack width due to corrosion. Indeed, EQ. 17, calibrated on the base of experimental results obtained with very low current density, has been applied to analytically estimate the crack width due to corrosion, for the specimens A1-D4.

The parameters necessary for the application of the model were evaluated according to the Model Code 2010 suggestions, based on the measured compressive strength. The value of the main properties is reported in Table 4.

The volumetric ratio of the oxide, with respect to iron $\left(\alpha_{1}\right.$ in Eq. 17) has been assumed equal to 2.00/2.15 since mainly ferrihydrite formed after the corrosion process. The comparison between the experimental and the analytical results expressed in terms of crack width is reported in Table $\mathbf{5}$, for both the specimens analysed in [42] and the ones discussed in this paper. It can be clearly noted how the crack width measured in specimens corroded with high current densities (higher than $500 \mu \mathrm{A} / \mathrm{cm}^{2}$ ) are greater than the ones obtained by the model, calibrated with reference to low densities, and then simulated the crack width due to natural corrosion.

\section{CONCLUSION}

In the present work, an experimental survey finalized to the evaluation of the influence of the current density in an artificial corrosion process is presented. The literature review shows, in fact, that some of the most significant results on the structural behavior of corroded structures come out from artificially corroded specimens, typically subjected to accelerated electrolytic corrosion test with different current intensities.

Steel rebars embedded in cylindrical concrete specimens were cast and subjected to different current intensities. After the corrosion test, the crack pattern was registered, the corrosion level on the reinforcement measured, the degradation morphology of the steel evaluated, and the typology of the corrosion products analyzed. The experimental tests showed that the prevalent corrosion product formed in the specimens was the ferrihydrite, characterized by a volumetric ratio, with respect to the iron, that varies between 2.00 and 2.15. Moreover, increasing the current intensity, then the corrosion rate, the cracks become wider and the corrosion morphology becomes more localized. This occurs because the oxides do not have time to spread in the concrete, so they accumulate at the interface and exert a considerable radial pressure. Therefore, as the current intensity increases, cracking occurs to lower and lower levels of corrosion.

Once the concrete cracks, the corrosion morphology becomes localized, with pits becoming deeper when the corrosion rate is increased.

Finally, an analytical model for the evaluation of crack width, based on the thick-cylinder model and calibrated with results obtained with very low current density is applied for the simulation of the experimental outcomes.

Based on the obtained results it is shown that current densities higher than $500 \mu \mathrm{A} / \mathrm{cm}^{2}$ lead to such values of crack widths, which are not representative of the actual conditions of elements subjected to natural corrosion.

\section{CONSENT FOR PUBLICATION}

Not applicable.

\section{AVAILABILITY OF DATA AND MATERIALS}

The data that support the findings of this study are available from the corresponding author, upon reasonable request.

\section{FUNDING}

None. 


\section{CONFLICT OF INTEREST}

The authors declare no conflict of interest, financial or otherwise.

\section{ACKNOWLEDGEMENTS}

The authors thank prof. Ilaria Cacciotti who carried out the $\mathrm{x}$-ray diffractometry measurements presented in this work.

\section{REFERENCES}

[1] W. Chai, W. Li, and H. Ba, "Experimental study on predicting service life of concrete in the marine environment", Open Civ. Eng. J., vol. 5, no. 1, pp. 93-99, 2011.

[http://dx.doi.org/10.2174/1874149501105010093]

[2] E.H. Wang, "Assessing serviceability improvement alternatives of existing structures", Open Constr. Build. Technol. J., vol. 5, pp. 113-122, 2011.

[http://dx.doi.org/10.2174/1874836801105010113]

[3] A. Bossio, and F. Bellucci, "Environmental degradation of reinforced concrete structures", Corros. Rev., vol. 37, pp. 1-2, 2019.

[http://dx.doi.org/10.1515/corrrev-2018-0091]

[4] A. Bossio, F. Fabbrocino, T. Monetta, G.P. Lignola, A. Prota, G. Manfredi, and F. Bellucci, "Corrosion effects on seismic capacity of reinforced concrete structures", Corros. Rev., vol. 37, pp. 45-56, 2019. [http://dx.doi.org/10.1515/corrrev-2018-0044]

[5] BRIME, Bridge management in Europe, research project no.: RO-97SC.2220, The European union: transport research and technological development, final report, 2001.

[6] FHWA. Deficient bridges by state and highway system, Online, URL http://www.fhwa.dot.gov/bridge/nbi/no10/defbr12.cfm, Federal Highway Administration, U.S. Department of Transportation, 2012.

[7] Fib, Bond of reinforcement in concrete: state-of-art report. Bulletin, 10, 160-7. Task Group on Bond Models, Lausanne, Switzerland: International Federation for Struct. Concrete (Lond.), 2000.

[8] M.G. Stewart, and D.V. Val, "Multiple limit states and expected failure costs for deteriorating reinforced concrete bridges", J. Bridge Eng., vol. 8, no. 6, pp. 405-415, 2003.

[http://dx.doi.org/10.1061/(ASCE)1084-0702(2003)8:6(405)]

[9] Fib, Model code for service life design. Technical Report fib bulletin 34. Lausanne, Switzerland: International Federation for Struct. Concrete (Lond.),2006

[10] C. Andrade, C. Alonso, and F.J. Molina, "Cover cracking as a function of bar corrosion: Part I-Experimental test", Mater. Struct., vol. 26, no. 8, pp. 453-464, 1993

[http://dx.doi.org/10.1007/BF02472805]

[11] F.J. Molina, C. Alonso, and C. Andrade, "Cover cracking as a function of rebar corrosion: part II-numerical model", Mater. Struct., vol. 26, no. 9, pp. 532-548, 1993. [http://dx.doi.org/10.1007/BF02472864]

[12] C. Andrade, A. Cesetti, G. Mancini, and F. Tondolo, "Estimation of corrosion attack in reinforced concrete by means of crack opening", Struct. Concr., vol. 17, no. 4, pp. 533-540, 2016.

[http://dx.doi.org/10.1002/suco.201500114]

[13] T. Liu, and R.W. Weyers, "Modeling the dynamic corrosion process in chloride contaminated concrete structures", Cement Concr. Res., vol. 28, no. 3, pp. 365-379, 1998 .

[http://dx.doi.org/10.1016/S0008-8846(98)00259-2]

[14] T. El Maaddawy, and K. Soudki, "A model for prediction of time from corrosion initiation to corrosion cracking", Cement Concr. Compos., vol. 29 , no. 3 , pp. $168-175,2007$.

[http://dx.doi.org/10.1016/j.cemconcomp.2006.11.004]

[15] K. Bhargava, A.K. Ghosh, Y. Mori, and S. Ramanujam, "Analytical model for time to cover cracking in RC structures due to rebar corrosion", Nucl. Eng. Des., vol. 236, no. 11, pp. 1123-1139, 2006. [http://dx.doi.org/10.1016/j.nucengdes.2005.10.011]

[16] K. Tuutti, "Service life of structures with regard to corrosion of embedded steel", Special Publication, vol. 65, pp. 223-236, 1980.

[17] R.E. Weyers, "Service life model for concrete structures in chloride laden environments", Mater. J., vol. 95, no. 4, pp. 445-453, 1998.

[18] S.J. Pantazopoulou, and K.D. Papoulia, "Modeling cover-cracking due to reinforcement corrosion in RC structures", J. Eng. Mech., vol. 127, no. 4, pp. 342-351, 2001.

[http://dx.doi.org/10.1061/(ASCE)0733-9399(2001)127:4(342)]

[19] X.H. Wang, and X.L. Liu, "Modelling effects of corrosion on cover cracking and bond in reinforced concrete", Mag. Concr. Res., vol. 56, no. 4, pp. 191-199, 2004.

[http://dx.doi.org/10.1680/macr.2004.56.4.191]

[20] K. Bhargava, A.K. Ghosh, Y. Mori, and S. Ramanujam, "Modeling of time to corrosion-induced cover cracking in reinforced concrete structures", Cement Concr. Res., vol. 3, no. 11, pp. 2203-2218, 2005. [http://dx.doi.org/10.1016/j.cemconres.2005.06.007]

[21] K. Bhargava, A.K. Ghosh, Y. Mori, and S. Ramanujam, "Model for cover cracking due to rebar corrosion in RC structures", Eng. Struct., vol. 28 , no. 8, pp. 1093-1109, 2006.

[http://dx.doi.org/10.1016/j.engstruct.2005.11.014]

[22] L. Chernin, D.V. Val, and K.Y. Volokh, "Analytical modelling of concrete cover cracking caused by corrosion of reinforcement", Mater. Struct., vol. 43, no. 4, pp. 543-556, 2010.

[http://dx.doi.org/10.1617/s11527-009-9510-2]

[23] C. Lu, W. Jin, and R. Liu, "Reinforcement corrosion-induced cover cracking and its time prediction for reinforced concrete structures", Corros. Sci., vol. 53, no. 4, pp. 1337-1347, 2011. [http://dx.doi.org/10.1016/j.corsci.2010.12.026]

[24] A. Jamali, U. Angst, B. Adey, and B. Elsener, "Modeling of corrosioninduced concrete cover cracking: A critical analysis", Constr. Build. Mater., vol. 42, pp. 225-237, 2013.

[http://dx.doi.org/10.1016/j.conbuildmat.2013.01.019]

[25] M.B. Otieno, H.D. Beushausen, and M.G. Alexander, "Modelling corrosion propagation in reinforced concrete structures-A critical review", Cement Concr. Compos., vol. 33, no. 2, pp. 240-245, 2011. [http://dx.doi.org/10.1016/j.cemconcomp.2010.11.002]

[26] X. Du, L. Jin, and R. Zhang, "Modeling the cracking of cover concrete due to non-uniform corrosion of reinforcement", Corros. Sci., vol. 89, pp. 189-202, 2014.

[http://dx.doi.org/10.1016/j.corsci.2014.08.025]

[27] A. Bossio, T. Monetta, F. Bellucci, G.P. Lignola, and A. Prota, "Modeling of concrete cracking due to corrosion process of reinforcement bars", Cement Concr. Res., vol. 71, pp. 78-92, 2015.

[http://dx.doi.org/10.1016/j.cemconres.2015.01.010]

[28] A. Bossio, G.P. Lignola, F. Fabbrocino, T. Monetta, A. Prota, F. Bellucci, and G. Manfredi, "Nondestructive assessment of corrosion of reinforcing bars through surface concrete cracks", Struct. Concr., vol. 18, no. 1, pp. 104-117, 2017.

[http://dx.doi.org/10.1002/suco.201600034]

[29] L.A. Clark, and M. Saifullah, "Effect of corrosion on reinforcement bond strength", In: Proceedings of 5th international conference on structural faults and repairs, . Engineering Technical Press: Edinburgh, vol. 3, pp. 113-119, 1993.

[30] M. Saifullah, and L.A. Clark, "Effect of corrosion rate on the bond strength of corroded reinforcement", Corros. Corros. Protect. Steel Concrete, pp. 591-602, 1994.

[31] C. Alonso, C. Andrade, J. Rodriguez, and J.M. Diez, "Factors controlling cracking of concrete affected by reinforcement corrosion", Mater. Struct., vol. 31, no. 7, pp. 435-441, 1998. [http://dx.doi.org/10.1007/BF02480466]

[32] T.A. El Maaddawy, and K.A. Soudki, "Effectiveness of impressed current technique to simulate corrosion of steel reinforcement in concrete", J. Mater. Civ. Eng., vol. 15, no. 1, pp. 41-47, 2003.

[http://dx.doi.org/10.1061/(ASCE)0899-1561(2003)15:1(41)]

[33] J. Rodriguez, L.M. Ortega, and J. Casal, "Load carrying capacity of concrete structures with corroded reinforcement", Constr. Build. Mater., vol. 11, no. 4, pp. 239-248, 1997.

[http://dx.doi.org/10.1016/S0950-0618(97)00043-3]

[34] J. Rodriguez, L.M. Ortega, and J. Casal, "Corrosion of reinforcement and service life of concrete structures", In: Proceedings of 7 th International Conference on DBMC, vol. 1, pp. 117-126, 1996.

[35] K. Vu, M.G. Stewart, and J. Mullard, "Corrosion-induced cracking: experimental data and predictive models", ACI Struct. J., vol. 102, no. 5, p. 719, 2005 .

[36] D.V. Val, L. Chernin, and M.G. Stewart, "Experimental and numerical investigation of corrosion-induced cover cracking in reinforced concrete structures", J. Struct. Eng., vol. 135, no. 4, pp. 376-385, 2009. [http://dx.doi.org/10.1061/(ASCE)0733-9445(2009)135:4(376)]

[37] N.F. Ortega, J.M. Moro, and R. Meneses, "Corrosion in concrete structures with permanent deformation in marine environment", Open Constr. Build. Technol. J., vol. 11, no. 1, 2017.

[http://dx.doi.org/10.2174/1874836801711010014]

[38] T. Vidal, A. Castel, and R. Francois, "Analyzing crack width to predict corrosion in reinforced concrete", Cement Concr. Res., vol. 34, no. 1, pp. 165-174, 2004.

[http://dx.doi.org/10.1016/S0008-8846(03)00246-1] 
[39] T. Vidal, A. Castel, and R. Francois, "Corrosion process and structural performance of a 17 year old reinforced concrete beam stored in chloride environment", Cement Concr. Res., vol. 37, no. 11, pp. 1551-1561, 2007.

[http://dx.doi.org/10.1016/j.cemconres.2007.08.004]

[40] R. Zhang, A. Castel, and R. François, "Concrete cover cracking with reinforcement corrosion of RC beam during chloride-induced corrosion process", Cement Concr. Res., vol. 40, no. 3, pp. 415-425, 2010.

[http://dx.doi.org/10.1016/j.cemconres.2009.09.026]

[41] I. Khan, R. François, and A. Castel, "Prediction of reinforcement corrosion using corrosion induced cracks width in corroded reinforced concrete beams", Cement Concrete Res, vol. 56, pp. 84-96, 2014

[42] S. Coccia, S. Imperatore, and Z. Rinaldi, "Influence of corrosion on the bond strength of steel rebars in concrete", Mater. Struct., vol. 49, no. 1-2, pp. 537-551, 2016.

[http://dx.doi.org/10.1617/s11527-014-0518-x]

[43] A.J. Bigaj, "Structural dependence of rotations capacity of plastic hinges in RC beams and slabs", Ph.D. Thesis, Delft University Press, the Netherlands, 1999.

[44] P.E. Roelfstra, and F.H. Wittmann, "Numerical modelling of fracture of concrete", In: Transactions of the 9th international conference on structural mechanics in reactor technology, vol. H, 1987.

\section{(C) 2019 Imperatore and Rinaldi.}

This is an open access article distributed under the terms of the Creative Commons Attribution 4.0 International Public License (CC-BY 4.0), a copy of which is available at: https://creativecommons.org/licenses/by/4.0/legalcode. This license permits unrestricted use, distribution, and reproduction in any medium, provided the original author and source are credited. 